\title{
Long-term comparison of human insulin analogue B10Asp and soluble human insulin in IDDM patients on a basal/bolus insulin regimen
}

\author{
F. S. Nielsen ${ }^{1}$, L. N. Jorgensen ${ }^{2}$, M. Ipsen ${ }^{1}$, A. I. Voldsgaard ${ }^{1}$, H.-H. Parving ${ }^{1}$ \\ ${ }^{1}$ Steno Diabetes Center, Gentofte, Denmark \\ ${ }^{2}$ Novo Nordisk A. S., Bagsværd, Denmark
}

Summary Recombinant DNA technology allows the production of insulin analogues with faster absorption rates from subcutaneous tissue as compared to soluble human insulin. The human insulin analogue B10Asp (mono/dimeric) is absorbed twice as fast as soluble human insulin (hexameric). A double blind, randomised crossover study with a 1-month run-in period and two 2 -month treatment periods was performed in 21 male insulin-dependent diabetic (IDDM) patients aged 18-40 years in order to compare the metabolic control obtained with equimolar doses of the analogue B10Asp vs soluble human insulin (Actrapid) given as mealtime insulin and intermediate acting isophane insulin (Protaphane) at bedtime. At the end of each 2-month study period, the patients were admitted to the metabolic ward. We found significantly higher plasma insulin/analogue levels after breakfast, lunch and dinner with B10Asp as compared to Actrapid $(p<0.05)$. The plasma insulin/analogue levels were significantly lower before lunch and dinner with B10Asp as compared to Actra- pid $(p<0.05)$. Also, the plasma insulin/analogue level tended to be lower at bedtime when comparing B10Asp to Actrapid. The 24-h blood glucose profiles showed identical fasting blood glucose, significantly lower blood glucose after breakfast with the analogue $(p<0.05)$, no differences in blood glucose after lunch and dinner but a significantly higher blood glucose at midnight using the analogue $(p<0.05)$. The overall 24-h mean blood glucose concentrations, the daily insulin dose, $\mathrm{HbA}_{1 \mathrm{c}}$, diet, home blood glucose monitoring and frequency of hypoglycaemia were almost identical in the two treatment periods. In conclusion, the overall glycaemic control remained unchanged and quite good when Actrapid was exchanged dose for dose with the insulin analogue B10Asp in IDDM patients treated with a basal bolus regime. [Diabetologia (1995) 38: 592-598]

Key words IDDM, insulin analogues, metabolic control.
Several randomised studies dealing with small numbers of insulin-dependent diabetic (IDDM) patients have unanimously suggested that the initiation and progression of the early stages of diabetic retinopathy and nephropathy can be delayed or even prevented by strict metabolic control [1-10]. The DCCT trial has confirmed and extended these studies by demon-

Received: 7 June 1994 and in revised form: 18 October 1994

Corresponding author: Dr. F. S. Nielsen, Steno Diabetes Center, Niels Steensens Vej 2, DK-2820 Gentofte, Denmark Abbreviations: IDDM, Insulin-dependent diabetes mellitus; RIA, radioimmunoassay; IGF-I, insulin-like growth factor-I. strating that intense insulin therapy effectively delayed the onset and slowed the progression of diabetic retinopathy, nephropathy and neuropathy in 1441 IDDM patients [11]. Intensive therapy was conducted using an external insulin pump or by three or more daily insulin injections (basal/bolus regime) and guided by frequent blood glucose monitoring. Several clinic-based studies have demonstrated that the basal/bolus treatment regime is appreciated by IDDM patients in general [12-14].

In non-diabetic subjects, meal ingestion is followed rapidly by a rise in plasma insulin concentration, which reaches a peak within 30-60 min and returns to baseline within $4-5 \mathrm{~h}[15,16]$. In contrast, subcuta- 
neous injections of soluble insulin, in both non-diabetic [17] and diabetic subjects [18], results in a slower rise in plasma insulin concentration and a lower peak at 90-120 min; also the level tends to be inappropriately high $3-5 \mathrm{~h}$ after injection [19]. In diabetic subjects, the initial low plasma insulin level contributes to an excessive postprandial glucose excursion, and a subsequent long period of high insulin levels predisposes to late hypoglycaemia.

Soluble human insulin exists mainly in the hexameric form in pharmaceutical concentrations [20], and the initial delay in absorption has been attributed to the rate of dissociation of hexameric units into dimeric and monomeric molecules at the subcutaneous injection site $[21,22]$. Recombinant DNA technology allows the production of insulin analogues with faster absorption rates from subcutaneous tissue as compared to soluble human insulin [23]. The human insulin analogue B10Asp (mono/dimeric) in which B10 histidine is substituted by aspartate is absorbed twice as fast as soluble human insulin from the subcutaneous injection site in both non-diabetic subjects [24] and in IDDM patients [25]. Clamp studies in healthy men have demonstrated that the analogue B10Asp has the same bioavailability but a faster onset of action as compared to soluble human insulin [26].

The aim of our double-blind, randomized crossover study was to evaluate the long-term (2-month) effect on metabolic control of the fast acting insulin analogue B10Asp as compared to soluble human insulin (Actrapid) in IDDM patients on a basal bolus regimen. The fast-acting insulins were given less than $5 \mathrm{~min}$ before the three main meals.

\section{Subjects and methods}

Subjects. Twenty-four IDDM patients fulfilling the following criteria were consecutively enrolled from the outpatient clinic at Steno Diabetes Center. Inclusion criteria were: age 18 to 40 years, male, duration of diabetes more than 1 year, treated with a multiple injection regimen for longer than 6 months, haemoglobin $\mathrm{A}_{1 \mathrm{c}}\left(\mathrm{HbA}_{1 \mathrm{c}}\right)$ less than $10 \%$, body mass index (BMI) less than $27 \mathrm{~kg} / \mathrm{m}^{2}$ and a stable metabolic control ( $\mathrm{HbA}_{1 \mathrm{c}}$ varying less than $1 \%$ for the previous 6 months). Exclusion criteria were: history of hypoglycaemic unawareness, local lipodystrophy, urinary albumin excretion greater than $300 \mathrm{mg} / 24 \mathrm{~h}$, proliferative retinopathy, other medication or any concurrent disease. All patients had a stimulated C-peptide value lower than $0.60 \mathrm{pmol} / \mathrm{ml}$ [27]. The glucagon/C-peptide test was carried out after an overnight fast. Blood samples for plasma C-peptide determination were obtained before and $6 \mathrm{~min}$ after an i. v. bolus injection of $1 \mathrm{mg}$ glucagon (Novo Nordisk, Bagsværd, Denmark) as described previously [27]. The study was completed by 21 patients; 3 patients were excluded, one patient because of a gastroscopic verified ulcus duodenus at the first visit, a second because his $\mathrm{HbA}_{1 \mathrm{c}}$ rose more than $3 \%$ during the run-in period; the reason for this increase was unknown. The third patient had an infected toenail at the first hospitalisation and required antibiotic and surgical treatment. The results from the three excluded patients were not used in the calculations. All the subjects included in the study were Caucasian, and all gave informed consent to participate in the study. The study was approved by the local ethical committee.

Methods. We performed a double-blind randomised, crossover study with an open 4-week run-in period during which the patients were treated with soluble human insulin (Actrapid HM; $600 \mathrm{nmol} / \mathrm{ml}(100 \mathrm{IU} / \mathrm{ml})$, Novo Nordisk, Bagsværd, Denmark) less than $5 \mathrm{~min}$ before breakfast, lunch and dinner and with intermediate acting isophane insulin (Protaphane HM, $600 \mathrm{nmol} / \mathrm{ml}$; (100 IU/ml), Novo Nordisk) at bedtime. All mealtime insulin was injected subcutaneously in a skinfold at a $45^{\circ}$ angle with a Novo Pen using a $12.5 \mathrm{~mm}$-long cannula in the abdominal wall. Bedtime insulin was injected in a similar way in the thigh.

After the run-in period the patients were randomised to either Actrapid or insulin analogue B10Asp $(600 \mathrm{nmol} / \mathrm{ml}$ $(100 \mathrm{IU} / \mathrm{ml})$, Novo Nordisk) as premeal insulin for 8 weeks; thereafter the patients were taken to the metabolic ward where 24-h profiles of blood glucose and plasma free-insulin/ analogue were obtained, and $\mathrm{HbA}_{1 c}$ were measured. The subjects were then changed to the other type of premeal insulin for another 8 weeks and finally taken to the metabolic ward for 24-h blood glucose and plasma free-insulin/analogue profiles and $\mathrm{HbA}_{1 \mathrm{c}}$ measurement. During hospital admission the patients received a diet according to the information they had given to the dietician. The individual diets were isocaloric at the two admissions. During the 2 days prior to admission to the metabolic ward we collected seven capillary blood samples on each day from each patient (blood glucose was measured, preprandially, $90 \mathrm{~min}$ postprandially and before bedtime). The samples were sent to our laboratory for analysis.

During the run-in period the patients were seen in the outpatient clinic at day 0 , week 2 and for randomisation at week 4. During the treatment periods, the patients were seen in the outpatient clinic at weeks 1 and 2 . A telephone consultation was performed at weeks 3 and 6 . The day before each visit to the outpatient clinic, the patients performed a 7-point blood glucose profile with a Reflolux II M, Boehringer-Mannheim $\mathrm{GmbH}$, (Mannheim, Germany). The insulin doses were recorded and adjusted according to the following goals: fasting blood glucose 4 to $7 \mathrm{mmol} / \mathrm{l}$ and postprandial blood glucose level less than $11 \mathrm{mmol} / \mathrm{l}$. Hypoglycaemic events for the previous week were recorded and graded as mild if the patients could treat themselves with carbohydrate supplements, and graded as serious if third-party assistance was required. Mild hypoglycaemic events were recorded during each contact with the patients. Serious hypoglycaemic events were recorded for the complete study. At each clinic visit injection sites were inspected.

The patients were instructed to continue their usual diet (three main meals and two to three snacks) and their everyday activities. To ensure that no quantitative or qualitative changes had occurred in their diet the patients were interviewed by a dietician and their body weight recorded at entry, crossover and at the end of the study.

Laboratory analysis. During the hospital admissions blood glucose and plasma insulin/analogue were measured each hour during the daytime ( 07.00 to 24.00 hours) and each $2 \mathrm{~h}$ during the nighttime ( 00.00 to 07.00 hours). Blood glucose concentrations were determined by the hexokinase method [28]. $\mathrm{HbA}_{1 \mathrm{C}}$ was determined by high performance liquid chromatography (DIAMAT Analyzer; Bio-Rad, Richmond, Calif., USA) [29] where the normal range of $\mathrm{HbA}_{1 \mathrm{C}}$ in our laboratory is 4.1$6.1 \%$.

Blood samples for plasma insulin/analogue concentration measurement were centrifuged for $10 \mathrm{~min}$ at $4^{\circ} \mathrm{C}$ and anti- 
Table 1. Clinical characteristics of 21 male IDDM patients completing 8 weeks treatment with Actrapid and insulin analogue B10Asp

\begin{tabular}{ll}
\hline Age (years) & $28(23-33)$ \\
Duration of diabetes (years) & $11(2-28)$ \\
Duration of basal/bolus treatment (years) & $3.5(1-5)$ \\
$\mathrm{HbA}_{1 \mathrm{c}}(\%)^{\mathrm{a}}$ & $8.0 \pm 1.2$ \\
$\mathrm{BMI}^{\mathrm{a}}\left(\mathrm{kg} / \mathrm{m}^{2}\right)^{\mathrm{a}}$ & $23.6 \pm 1.8$ \\
Retinopathy $(\mathrm{n})($ nil/simplex/proliferative) & $0 / 21 / 0$ \\
Urinary albumin excretion (mg/24 h) & $17(10-25)$ \\
\hline
\end{tabular}

Median (range), except ${ }^{\mathrm{a}}$ mean \pm SD
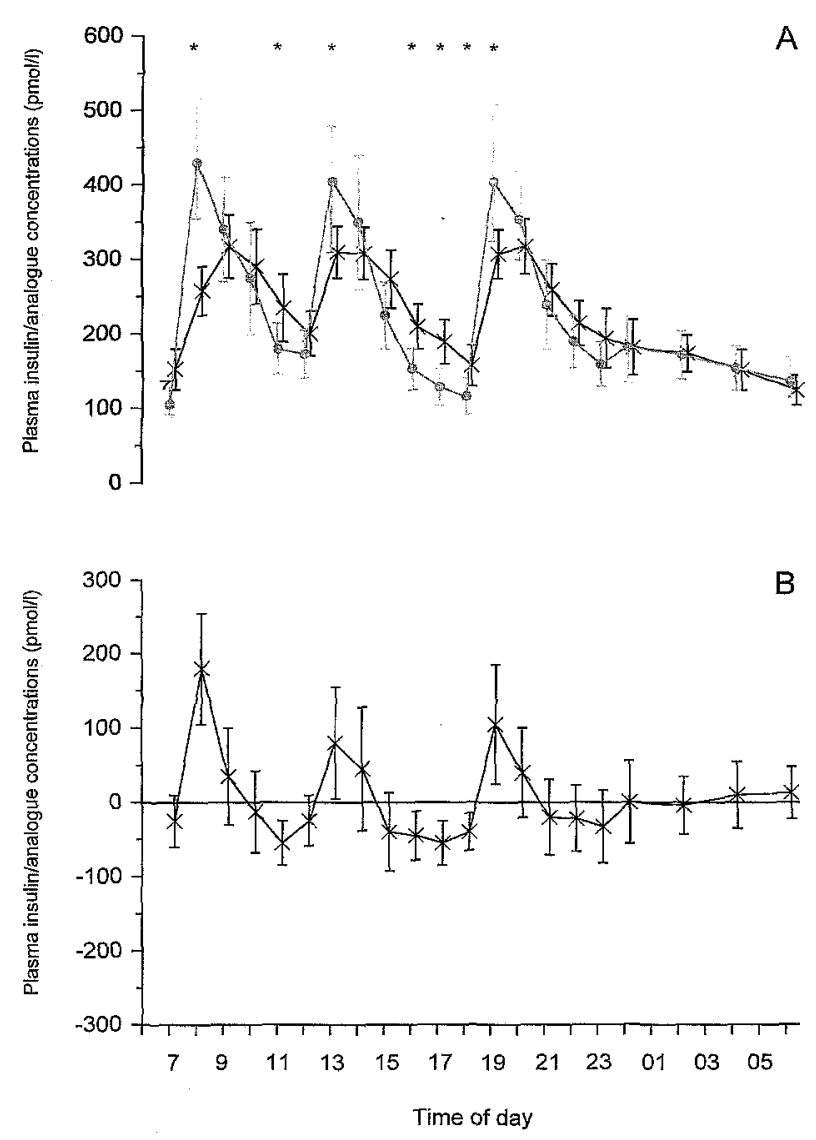

Fig. 1. A Twenty-four hour plasma free insulin/analogue concentrations (pmol/1) in 21 IDDM patients treated with soluble human insulin (Actrapid) $* *$ or insulin analogue B10Asp $\longrightarrow \bullet-$ for 8 weeks. Values given as mean \pm 2 SEM. $* p<0.05$ comparing the two insulins. B B10Asp - Actrapid. Values given as mean difference ( $95 \%$ confidence interval). Values obtained during hospital admission

bodies bound to insulin were precipitated by addition of a $300 \mathrm{~g} / \mathrm{l}$ polyethylene glycol solution to the plasma. These samples were stored at $-80^{\circ} \mathrm{C}$ for less than 1 month and then analysed for insulin levels. Plasma free insulin concentrations were measured by a radioimmunoassay (RIA) technique with coefficients of variation between 6 and $14 \%$ in the physiological range [30]. Plasma analogue concentrations were determined by standard RIA using M8309 antibody, 125-Imonoiodinated-insulin and analogue-calibrators, essentially as described by Heding [30]. M-value was calculated as described by Schlichtkrull et al. [31] using the 24-h blood glucose values from the hospital admissions. The following safety parameters were measured using standard methodology at entry, crossover and at the end of the study; yeast antibodies $\mathrm{IgG}$, lactate dehydrogenase, alkaline phosphatase, aspartate aminotransferase, creatinine, leucocytes and differential count, haemoglobin, haematocrit, cholesterol, high-density (HDL)-cholesterol, low-density (LDL)-cholesterol was calculated by the Friedewald equation [32], triglycerides, prothrombin, activated prothrombin, fibrinogen and thrombocytes. At the same time insulin antibodies $\operatorname{IgG}$, analogue B10Asp antibodies IgG were determined by anti-insulin (Novo Nordisk, Immunochemical Department, Cat. No.: 7351542) using mono-125I-(Tyr-A14)-Human Insulin or mono-125I-(Tyr-A14)-B10Asp.

At least three 24-h urine samples were collected. The urinary albumin concentration was determined by RIA with a single antibody [33]. Body mass index (BMI) was calculated as $\mathrm{kg}$ body weight/height $\mathrm{m}^{2}$. Retinopathy was assessed by fundus photography after pupillary dilation.

\section{Statistical analysis}

All data are given as mean \pm SD except 24 -h profiles of blood glucose and plasma insulin/analogue concentrations which are given as mean \pm 2 SEM. Comparison of normally distributed parameters was done using standard analysis of variance (ANOVA) for two crossover periods, hence evaluation of treatment differences were carried out as within patient comparisons. Area under the curve (AUC) was calculated by means of the trapezoid rule. Comparison of frequencies was done using Wilcoxon's signed rank test. A p-value (twotailed) less than 0.05 was considered significant. The study was designed to detect a difference of $0.5 \%$ in $\mathrm{HbA}_{1 \mathrm{c}}$ with a power of $90 \%($ alpha $=0.05)$ provided 21 patients completed the study. All calculations were made with a commercially available program (Statistical Analysis System, SAS Institute, Raleigh, N. C., USA).

\section{Results}

The clinical characteristics of the 21 male IDDM patients completing the study are shown in Table 1. The 24-h profiles of plasma free insulin/analogue levels for B10Asp and Actrapid are shown in Figure 1. We found significantly higher plasma insulin/analogue levels after breakfast, lunch and dinner with B10Asp as compared to Actrapid $(p<0.05)$. The plasma insulin/analogue levels were significantly lower before lunch and dinner $(p<0.05)$ and tended to be lower at bedtime with B10Asp as compared to Actrapid. There was no difference in the calculated area under the curve (AUC) comparing the two insulins $(p=0.70)$ during $24 \mathrm{~h}$. Furthermore, no differences were found comparing the two insulins between the meals and during the night.

The corresponding 24-h blood glucose profiles are shown in Figure 2. The fasting blood glucose was identical using the two fast-acting insulins. Blood glucose was significantly lower after breakfast comparing B10Asp to Actrapid $(p<0.05)$. There was no significant difference in blood glucose from lunch up to 21.00 hours using the two insulins. From 21.00 until 


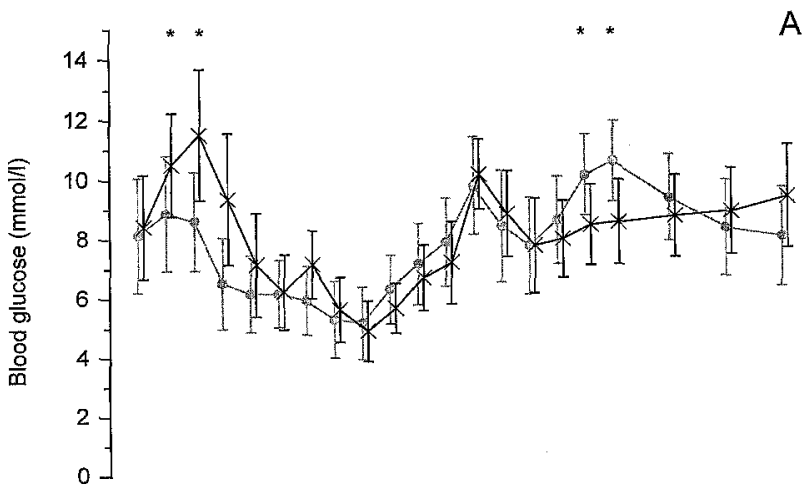

B

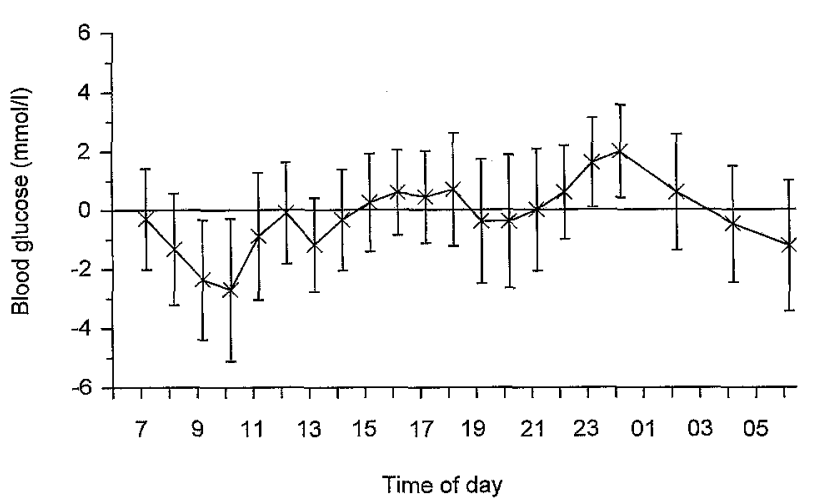

Fig.2. A Twenty-four hour blood glucose concentrations (mmol/l) in 21 IDDM patients treated with soluble human insulin (Actrapid) $-x \times x$ or insulin analogue B10Asp $\bullet \bullet \bullet-$ for 8 weeks. Values given as mean \pm 2 SEM. $* p<0.05$ comparing the two insulins. B B10Asp - Actrapid. Values given as mean difference ( $95 \%$ confidence interval). Values obtained during hospital admission

Table 2. Metabolic control in 21 male IDDM patients at the end of each 8-week treatment period

\begin{tabular}{lccl}
\hline Treatment period & B10Asp & Actrapid & $p$-value \\
\hline $\mathrm{HbA}_{1 \mathrm{c}}(\%)$ & $7.7 \pm 0.9$ & $7.8 \pm 0.6$ & $\mathrm{NS}$ \\
Mean blood glucose (mmol/1) & $7.8 \pm 2.3$ & $8.1 \pm 1.5$ & $\mathrm{NS}$ \\
M-value & $24 \pm 19$ & $26 \pm 14$ & $\mathrm{NS}$ \\
Triglycerides (mmol/l) & $1.0 \pm 0.6$ & $0.9 \pm 0.6$ & $\mathrm{NS}$ \\
Total cholesterol $(\mathrm{mmol} / \mathrm{l})$ & $4.2 \pm 0.8$ & $4.2 \pm 0.7$ & $\mathrm{NS}$ \\
HDL-cholesterol $(\mathrm{mmol} / \mathrm{l})$ & $1.4 \pm 0.3$ & $1.3 \pm 0.3$ & $\mathrm{NS}$ \\
LDL-cholesterol $(\mathrm{mmol} / \mathrm{l})$ & $2.4 \pm 0.7$ & $2.4 \pm 0.7$ & $\mathrm{NS}$ \\
\hline
\end{tabular}

Mean \pm SD

03.00 hours there was a rise in blood glucose levels during B10Asp as compared to Actrapid treatment. The difference reached statistical significance at 23.00 and 24.00 hours $(p<0.05)$. AUC was similar comparing the two insulins $(p=0.63)$ during $24 \mathrm{~h}$. Furthermore, no differences were found comparing the two insulins between the meals and during the night. Twenty-four h mean blood glucose and M-value were not different, comparing the two insulin treatments (Table 2).

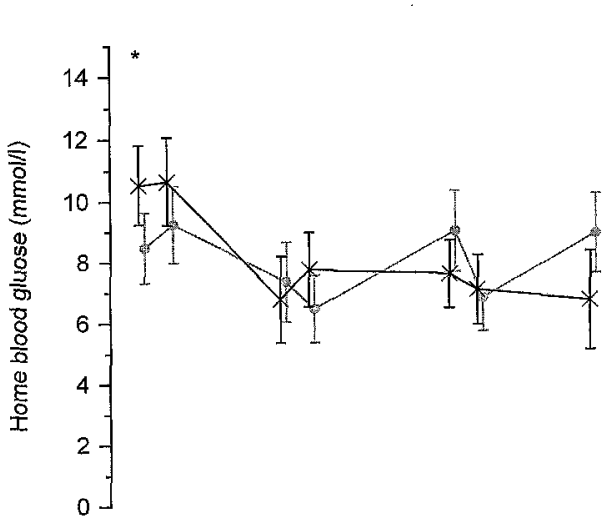

A

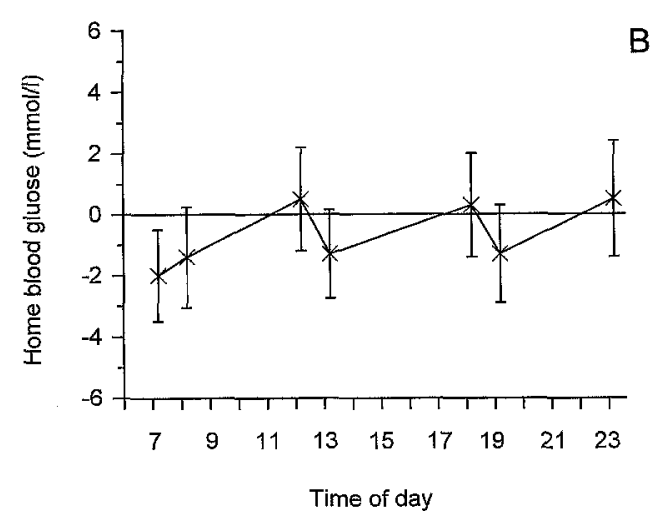

Fig. 3. A Home blood glucose concentrations ( $\mathrm{mmol} / \mathrm{l}$ ) in 21 IDDM patients treated with soluble human insulin (Actrapid) $* x *$ or insulin analogue B10Asp $\bullet \bullet-$. Values given as mean $\pm \mathrm{SEM}$. $* p<0.05$ comparing the two insulins. B B10Asp - Actrapid. Values given as mean difference (95\% confidence interval). Values obtained at home

The home blood glucose profiles, based on the seven samples per day sent to the hospital for analysis, (Fig.3) showed statistically significant lower fasting blood glucose comparing B10Asp to Actrapid $(p<0.05)$. Also, the blood glucose level was lower after breakfast, lunch and dinner comparing B10Asp to Actrapid but the differences did not reach statistical significance.

We found no statistically significant differences in $\mathrm{HbA}_{1 \mathrm{c}}$ and lipids comparing the two insulin regimens (Table 2). Insulin doses, BMI, hypoglycaemic events, total energy intake and snack consumption were not different comparing the two insulin (Table 3).

Insulin antibodies were higher comparing B10Asp to Actrapid using human insulin as tracer $19 \pm 14$ vs $17 \pm 12 \%(p<0.05)$, but not different using B10Asp as tracer $10 \pm 8$ vs $9 \pm 5 \%$. There was no difference in any of the safety parameters comparing the two insulins. No local reactions were observed at the injection sites. 
Table 3. Insulin dose, total energy intake and BMI in 21 male IDDM patients at the end of each treatment period

\begin{tabular}{lccl}
\hline Treatment period & B10Asp & Actrapid & $p$-value \\
\hline Insulin dose $(I U)$ & & & \\
morning & $10 \pm 4$ & $10 \pm 4$ & NS \\
lunch & $9 \pm 3$ & $9 \pm 3$ & NS \\
dinner & $12 \pm 4$ & $12 \pm 4$ & NS \\
bedtime & $21 \pm 4$ & $21 \pm 4$ & NS \\
Total energy & $8444 \pm 2223$ & $8440 \pm 2036$ & NS \\
intake (kJ) & & & \\
Number of snacks & $2.0 \pm 1.0$ & $2.5 \pm 1.0$ & NS \\
$\begin{array}{l}\text { Hypoglycaemic events (no.) } \\
\text { Mild (number/ }\end{array}$ & 1.4 & 1.3 & NS \\
$\begin{array}{l}\text { week/patient) } \\
\text { Severe (number }\end{array}$ & 0 & 3 & NS \\
whole study) & & & \\
BMI (kg/m ${ }^{2}$ ) & $23.2 \pm 1.7$ & $23.2 \pm 1.8$ & NS \\
\hline
\end{tabular}

Mean \pm SD

\section{Discussion}

Our long-term double blind randomised crossover study clearly showed a more physiological plasma insulin/analogue profile with the fast-acting insulin analogue B10Asp, as compared to soluble human insulin (Actrapid) in IDDM patients treated with a basal/bolus regime $[15,16]$. Even though there was a trend towards lower postprandial blood glucose values this beneficial effect of B10Asp was offset by higher blood glucose levels during the night resulting in an overall 24-h glycaemic control and $\mathrm{HbA}_{1 \mathrm{c}}$ nearly identical to that obtained during treatment with Actrapid. Both treatments resulted in a fairly well-controlled diabetes $\left(\mathrm{HbA}_{1 \mathrm{c}} 7.8 \%\right)$.

Absorption of soluble insulin from subcutaneous tissues is too slow to mimic the normal rapid increment of insulin in blood in response to a meal [1519]. Therefore the development of fast-acting analogues (monomeric/dimeric) was considered of potential major clinical importance. Acute studies in healthy men and male IDDM patients has revealed that B10Asp as compared to human soluble insulin is characterized by half-maximal action obtained within $40 \mathrm{~min}$ after subcutaneous injection vs $60 \mathrm{~min}$, higher metabolic clearance and shorter apparent plasma half-life and the same overall bioavailability. The in vitro insulin receptor affinity of B10Asp is $300 \%$ that of human insulin when assessed by binding to human hepatoma cells [34]. Despite the improved plasma insulin/analogue profiles no major impact on overall glycaemic control was observed in our study. This may in part be explained by the existence of a saturable endothelial cell barrier which hampers the passage of insulin from plasma to the interstitial fluid and target organ cells, thus delaying and diminishing the hypoglycaemic effect of an increased plasma insulin/analogue concentration [35].
At our hospital IDDM patients are generally instructed to inject soluble insulin $30 \mathrm{~min}$ before the three main meals. Before conducting the present study we performed an anonymous questionnaire in 100 consecutive IDDM patients on basal bolus regimen regarding their actual timing of pre-meal insulin injection [36]. Forty-five percent took insulin 0$10 \mathrm{~min}$ before meals, $25 \%$ between $11-20 \mathrm{~min}$ before meals and the remaining $30 \%$ of the patients more than 20 min before meals. These findings led us to choose the preprandial insulin injections of less than 5 min before the meals, allowing for the unique opportunity to conduct a double blind randomised study comparing the two fast-acting insulin preparations.

Previous attempts to obtain more physiological plasma insulin concentrations by enhancing the $a b-$ sorption of soluble insulin include local massage [37, $38]$, the use of jet injector devices [39, 40] or sprinkler needles [41] and injection of insulin with aprotinin [42]. The enhanced absorption occurs mainly due to increased regional blood flow and increased capillary surface area product available for insulin passage.

From acute studies $[25,43]$ the possibility of increased frequency of postprandial hypoglycaemia using a fast-acting analogue might be suspected. There was no difference in the frequency of mild hypoglycaemic events comparing the two insulins. To insure that hypoglycaemia was not prevented by an increase in energy intake, i.e. more snacks, the patients were interviewed by a dietician three times during the study. No changes occurred in total energy intake or consumption of snacks during the study. The insulin doses were the same using the two insulins. These two facts are consistent with the unchanged BMI during the study.

No differences were found in serum lipids comparing the two insulins. Likewise, no differences were found in the safety parameters. Higher levels of insulin antibodies were found with B10Asp but only when using human insulin as tracer and the ratios between the two treatments were not significantly different.

We observed no side effects using the insulin analogue B10Asp over an 8-week period. Supraphysiological and pharmaceutical concentrations of B10Asp have been shown to induce a dose-dependent carcinogenic effect in the mammary glands in female but not in male rats [44]. All patients (male) receiving B10Asp in our study will be followed-up by physical examination and mammography at the local oncology department for at least the next 10 years. The carcinogen effect of B10Asp is likely to be caused by the increased affinity of the analogue to the insulin-like growth factor-1 (IGF-1) receptors. In rat aortic cells, B10Asp is five times more potent regarding binding to the IGF-1 receptor and also more 
potent regarding incorporation of thymidine and stimulating cell growth as compared to soluble human insulin [45]. Therefore, future studies with B10Asp cannot be recommended.

In conclusion, despite differences in plasma insulin/analogue levels and 24-h blood glucose profiles, overall glycaemic control remained unchanged when Actrapid was exchanged dose for dose with the insulin analogue B10Asp. We found no side effects using B10Asp but animal studies have shown a dose-dependent carcinogenic effect of the analogue. The search for a fast-acting insulin analogue with low IGF-1 receptor affinity should be continued.

\section{References}

1. Eschewege E, Job D, Guyot-Argenton C, Aubry JP, Tchobroutsky $\mathrm{G}$ (1979) Delayed progression of diabetic retinopathy by divided insulin administration: a further follow up. Diabetologia 16: 13-15

2. Deckert T, Lauritzen T, Parving H-H, Christiansen JS (1984) Effect of two years of strict metabolic function in long-term insulin-dependent diabetes. Diabetic Nephropathy 3: 6-10

3. The Kroc Collaborative Study Group (1984) Blood glucose control and the evolution of diabetic retinopathy and albuminuria. N Engl J Med 311: 365-372

4. Beck-Nielsen H, Richelsen B, Mogensen CE (1985) Effect of insulin pump treatment for one year on renal function and retinal morphology in patients with IDDM. Diabetes Care 8: 585-589

5. Olsen T, Richelsen B, Ehlers N, Beck-Nielsen H (1987) Diabetic retinopathy after 3 years treatment with continous subcutaneous insulin infusion (CSII). Acta Ophtalmol 65: 185-189

6. Christensen CK, Sandahl Christiansen J, Schmidt A (1987) Effect of continuous subcutaneous insulin infusion on kidney function and size in IDDM patients: a 2-year controlled study. J Diab Compl 1: 91-95

7. Dahl-Jørgensen J, Hanssen KF, Kierulf P, Bjøro T, Sandvik L, Aagenaes $\varnothing$ (1988) Reduction of urinary albumin excretion after 4 years of continuous subcutaneous insulin infusion in insulin-dependent diabetes mellitus. Acta Endocrinol 117: 19-25

8. Verrillo A, de Teresa A, Martino C, Verrillo L, di Chiara G (1988) Long-term correction of hyperglycemia and progression of retinopathy in insulin dependent diabetes: a five-year randomized prospective study. Diabetes Research 8: 71-76

9. Reichard P, Berglund B, Britz A, Cars I, Nilsson BY, Rosenqvist $U$ (1991) Intensified conventional insulin treatment retards the microvascular complications of insulin-dependent diabetes mellitus (IDDM): the Stockholm Diabetes Intervention Study (SDIS) after 5 years. J Intern Med 230: 101-108

10. Wang PH, Lau J, Chalmers TC (1993) Meta-analysis of effects of intensive blood-glucose control on late complications of type 1 diabetes. Lancet 341: 1306-1309

11. The Diabetes Contact and Complication Trial Research Group (1993) The effect of intensive treatment of diabetes on the development and progression of long-term complications in insulin dependent diabetes mellitus. N Engl J Med 329: 977-986
12. Small M, MacRury S, Boal A, Paterson KR, MacCuish AC (1988) Comparison of conventional twice daily subcutaneous insulin administration and a multiple injection regimen (using the NovoPen ${ }^{\mathrm{TM}}$ ) in insulin-dependent diabetes mellitus. Diabetes Research 8: 85-89

13. Gall M-A, Mathiesen ER, Skøtt P, Musaeus L, Damm S, Beck-Nielsen H et al. (1989) Effect of multiple insulin injections with a pen injector on metabolic control and general well-being in insulin-dependent diabetes mellitus. Diabetes Research 11: 97-101

14. Houtzagers CMG, Berntzen PA, van der Stap $H$ et al. (1989) Efficacy and acceptance of two intensified conventional insulin therapy regimens: a long-term cross-over comparison. Diabet Med 6: 416-421

15. Eaton RP, Allen RC, Schade S, Standefer JC (1980) Normal insulin secretion: the goal of artificial insulin delivery systems? Diabetes Care 3: 270-273

16. Schade DS, Eaton RP, Spencer W (1980) Normalisation of plasma insulin in diabetic subjects with programmed insulin delivery. Diabetes Care 3: 9-14

17. Owens DR (1986) Human insulin: clinical pharmacological studies in normal man. MTP Press Lancaster pp. 46-70

18. Van Haeften TW, Bolli GB, Dimitridias GD, Gottesman IS, Horwitz DL, Gerich JE (1986) Effect of insulin antibodies and their kinetic characteristics on plasma free insulin dynamics in patients with diabetes mellitus. Metabolism 7: 649-656

19. Home PD, Pickup JC, Keen H, Alberti KGMM, Parson JA, Binder C (1981) Continuous subcutaneous insulin infusion: comparison of plasma insulin profiles after infusion or bolus injection of the mealtime dose. Metabolism 30: $439-442$

20. Blundell T, Dodson G, Hodgkin D, Mercola D (1972) Insulin: the structure in the crystal and its reflection in chemistry and biology. Adv Protein Chem 26: 279-402

21. Binder C (1969) Absorption of injected insulin. Acta Pharmacol Toxicol 17: 67-87

22. Mosekilde E, Jensen KS, Binder C, Pramming S, Thorsteinsson B (1989) Modeling absorbtion kinetics of subcutaneous injected soluble insulin. J Pharmacokinet Biopharm 17: 67-87

23. Brange J, Ribel U, Hansen JF et al. (1988) Monomeric insulins obtained by protein engineering and their medical implications. Nature 333: 679-682

24. Kang S, Brange J, Burch A, Vølund A, Owens DR (1991) Subcutaneous insulin absorption explained by insulin's physicochemical properties. Evidence from absorption studies of soluble human insulin and insulin analogues in humans. Diabetes Care 14: 942-948

25. Kang S, Creagh FM, Peters JR, Brange J, Vølund A, Owens DR (1991) Comparison of subcutaneous soluble human insulin and insulin analogues (AspB9, GluB27; AspB10; AspB28) on meal-related plasma glucose excursions in type I diabetic subjects. Diabetes Care 14: 571-577

26. Heinemann L, Starke AA, Heding L, Jensen I, Berger M (1990) Action profiles of fast onset insulin analogues. Diabetologia 33: 384-386

27. Hother-Nielsen O, Faber O, Sørensen NS, Beck-Nielsen H (1988) Classification of newly diagnosed diabetic patients as insulin-requiring or non-insulin-requiring based on clinical and biochemical variables. Diabetes Care 11: 531-537

28. Andersen I, Hannibal S (1983) Analytical and economical optimization of a glucose method with immobilized enzymes. J Automatic Chemistry 4: 188-192

29. Goldstein DE, Peth SB, England JD, Hess RL, Randall LH, DaCosta J (1980) Effects of acute changes in blood glucose on $\mathrm{HbA}_{1 \mathrm{c}}$. Diabetes 29: 623-628 
30. Heding LG (1972) Determination of total serum (IRI) in insulin-treated diabetic patients. Diabetologia 8: 260-266

31. Schlichtkrull J, Munch O, Jersild M (1965) The M-value, an index of blood sugar in diabetes. Acta Med Scand 177: 95102

32. Friedewald WT, Levy RI, Frederickson DS (1972) Estimation of the concentration of low-density lipoprotein cholesterol in plasma, without use of the preparative ultracentrifugation. Clin Chem 18: 499-502

33. Christensen C, Ørskov C (1984) Rapid screening PEG radioimmunoassay for quantification of pathological microalbuminuria. Diabetic Nephropathy 3: 92-94

34. Drejer K, Kruse V, Larsen UD (1988) Insulin analogs: binding to the human liver cell line, Hep G2. Diabetes Res Clin Pract 5 [Suppl 2]: 102-103 (Abstract)

35. Jansson PA, Fowelin JP, von Schenck HP, Smith UP, Lönnroth PN (1993) Measurement by microdialysis of the insulin concentration in subcutaneous interstitial fluid. Diabetes 42: 1469-1473

36. Jørgensen LN, Nielsen FS (1990) Timing of pre-meal insulins in diabetic patients on a multiple daily injection regimen. A questionnaire study. Diabetologia 33: A116 (Abstract)

37. Linde B (1986) Dissociation of insulin absorption and blood flow during massage of a subcutaneous injection site. Diabetes Care 6: 570-574

38. Dillon RS (1983) Improved serum insulin profiles in diabetic individuals who massaged their insulin injection sites. Diabetes Care 6: 399-401
39. Taylor R, Home PD, Alberti KGMM (1981) Plasma free insulin profiles after administration of insulin by jet and conventional syringe injections. Diabetes Care 4: 377-379

40. Pehling GB, Gerlich JE (1984) Comparison of plasma insulin profiles after administration of insulin by jet spray and conventional needle in patients with insulin-dependent diabetes mellitus. Mayo Clin Proc 59: 751-754

41. Edsberg B, Herly D, Hildebrandt P, Kühl C (1987) Insulin bolus given by sprinkler needle: effect on absorption and glycaemic responce to a meal. BMJ 294: 1373-1376

42. Linde B, Gunnarsson R (1985) Influence of aprotinin on insulin absorption and subcutaneous blood flow in type 1 (insulin-dependent) diabetes. Diabetologia 28: 645-648

43. Kang S, Brange J, Burch A, Vølund A, Owens DR (1991) Absorption kinetics and action profiles of subcutaneously administered insulin analogues (AspB9, GluB27, AspB10, AspB28) in healthy subjects. Diabetes Care 14: 1057-1065

44. Jørgensen LN, Didriksen LH, Drejer K (1992) Carcinogen effect of the human insulin analogue B10 Asp in female rats. Diabetologia 35 [Suppl 1]: A3 (Abstract)

45. Bornfeldt KE, Gidlof RA, Wasteson A, Lake M, Skottner A, Arnqvist HJ (1991) Binding and biological effects of insulin, insulin analogues and insulin-like growth factors in rat aortic smooth muscle cell. Comparison of maximal growth promoting activities. Diabetologia [Suppl] 34: 307313 